\title{
Serum sIL-2R May Predict the Prognosis of Chronic Obstructive Pulmonary Disease Exacerbation
}

\section{Zhang Yue}

Xinhua Hospital Affiliated to Shanghai Jiao Tong University School of Medicine, Shanghai, China

\section{Lianping Ren}

Xinhua Hospital Affiliated to Shanghai Jiao Tong University School of Medicine, Shanghai, China Jinyuan Sun

Xinhua Hospital Affiliated to Shanghai Jiao Tong University School of Medicine, Shanghai, China Xuejun Guo ( $\nabla$ guoxuejun@xinhuamed.com.cn )

Xinhua Hospital Affiliated to Shanghai Jiao Tong University School of Medicine, Shanghai, China Fengfeng Han

Xinhua Hospital Affiliated to Shanghai Jiao Tong University School of Medicine, Shanghai, China

\section{Research Article}

Keywords: chronic obstructive pulmonary disease, exacerbation, hypercapnia,solubleinterleukin-2 receptor, predictive factor

Posted Date: January 7th, 2021

DOl: https://doi.org/10.21203/rs.3.rs-137114/v1

License: (c) (i) This work is licensed under a Creative Commons Attribution 4.0 International License. Read Full License 


\section{Serum sIL-2R may predict the prognosis of chronic obstructive pulmonary disease exacerbation}

\section{Authors/Affiliations:}

Yue Zhang ${ }^{1}$, Lianping Ren, Jinyuan Sun, Xuejun Guo, Fengfeng Han.

Department of Respiratory Medicine, Xinhua Hospital Affiliated to Shanghai Jiao Tong University School of Medicine, Shanghai 200092, China.

\section{Corresponding author:}

Xuejun Guo (guoxuejun@xinhuamed.com.cn)

Fengfeng Han (hanfengfeng@xinhuamed.com.cn)

\section{Correspondence author:}

Department of Respiratory Medicine, Xinhua Hospital Affiliated to Shanghai Jiao Tong University School of Medicine, 1665 Kong Jiang Road, Shanghai 200092, P. R.

China.

Tel: $+86-21-25078999-7373$ 


\begin{abstract}
Background: The exacerbation of chronic obstructive pulmonary disease (COPD) is a heterogeneous phenomenon associated with inflammation and clinical parameters. Knowing the predictors of poor prognosis in patients with COPD could help to provide adequate intensive therapy and closer follow-up. The aim of this study was to disclose the correlation between the serum soluble IL-2R (sIL-2R) and prognosis in COPD exacerbation.
\end{abstract}

Methods: Two hundred and ninety-four patients with COPD exacerbation were recruited between December 2017 and December 2019. Patients underwent lung function (spirometry) assessment, demographic and clinical parameters were collected, and a metabolic profile and inflammatory profile were created. Adverse outcomes included the following: death during hospitalisation or 1-month follow-up, intensive care unit admission, invasive or non-invasive mechanical ventilation and COPD-related emergency visit or readmission within 1 month after discharge. Univariate and multivariate analyses were performed to identify factors related to adverse outcomes in COPD exacerbation. The receiver operating characteristic (ROC) curve was used to determine the optimal diagnostic threshold for the predictors.

Results: We enrolled 294 patients, of whom 157 and 137 had good outcomes and adverse outcomes, respectively. We demonstrated that patients with poor outcomes in COPD exacerbation had a higher smoking index or concomitant congestive heart disease, and patients with hypercapnia were more likely to have a worse prognosis. An 
elevated level of sIL-2R at admission was an independent risk predictor for poor prognosis in COPD exacerbation with a cut-off value of $860 \mathrm{U} / \mathrm{mL}$. Hypercapnia was the strongest predictor with a cut-off value of $54.25 \mathrm{mmHg}$.

Conclusions: The presence of hypercapnia and elevated level of sIL-2R increased the risk of the adverse outcomes in COPD exacerbation.

Keywords: chronic obstructive pulmonary disease, exacerbation, hypercapnia, soluble interleukin-2 receptor, predictive factor

\section{Background}

Chronic obstructive pulmonary disease (COPD) is a disease characterized by persistent airflow limitation, which is a systemic disease with a rising prevalence and mortality. In China, the prevalence of COPD in people over 40 years old is 13.6\%.WHO reports that COPD will become the third and fifth leading cause of death and disability globally by 2020 [1]. Acute exacerbations often occur in patients with COPD, and it has been demonstrated that acute exacerbations of COPD are a major clinical risk factor for increased morbidity and mortality in the future [2]. The Global Initiative on Chronic Obstructive Lung Disease (GOLD) has stated that prevention and treatment of exacerbations should be a key goal in COPD management [3].

However, the severity, evolution process and the results of COPD exacerbations may differ significantly between patients. Some patients have good outcomes and the 
illness can be controlled in a short period of time, while others may be hospitalised for long periods of time or even die, and this would increase the cost of managing the disease. Therefore, the identification of risk factors for bad outcomes could help in distinguishing those patients who require more intense management, which could reduce the social-economic burden and improve the patients' quality of survival. Although some clinical factors have been identified that are associated with frequent exacerbations of COPD [4], the reasons for poor prognosis in patients with acute exacerbations of COPD remain unclear. This is because COPD is a complex and heterogeneous disease. There are many kinds of cells in the lung, such as alveolar macrophages, neutrophils, $\mathrm{T}$ lymphocytes and mast cells. These cells are activated and can release a variety of inflammatory cytokines, which are involved in the pathogenesis and progression of COPD. Apart from local pulmonary inflammation, COPD is also a systemic inflammatory disease involving a variety of inflammatory factors [5]. Some researches about these inflammatory factors did provide many novel ideas about the pathogenesis of COPD. To date, however, there are no objective biomarkers that could suggest the disease activity or poor prognosis in COPD exacerbation.

The purpose of this study was to search for more sensitive and specific markers to predict the poor prognosis in COPD exacerbations, helping clinicians stratify the risk of COPD acute exacerbations, and to develop targeted interventions. 


\section{Methods}

\section{Ethics statement}

The study protocol was approved by the Human Research Ethics Committee of the Xinhua Hospital affiliated to Shanghai Jiaotong University Medical College (XHEC-C-2017-085). Written informed consent was obtained from each participant. All experiments were performed in accordance with relevant guidelines and regulations.

\section{Study subjects}

Two hundred and ninety-four patients with COPD exacerbation from the inpatient department of Xinhua Hospital in Shanghai were recruited between December 2017 and December 2019. All patients were diagnosed with COPD at least six years earlier. The diagnosis and classification of COPD were based on the 2017 Global Initiative for Obstructive Lung Disease (GOLD) guideline criteria: (a) forced expiratory volume/forced vital capacity $\left(\mathrm{FEV}_{1} / \mathrm{FVC}\right)<70 \%$ and (b) the increase of $\mathrm{FVC}$ or $\mathrm{FEV}_{1}$ $<12 \%$ or $200 \mathrm{~mL}$ after inspiring bronchodilator $\beta$-agonist (200 mg salbutamol) [3].

An exacerbation of COPD was defined as a COPD-related episode with: 1) hospitalisation; 2) emergency room (ER) visit; or 3) the need for oral corticosteroids (OCS) and/or antibiotics for at least 3 days [6]. Frequent exacerbation was defined as $\geq$ 2 exacerbations per year. All patients discharged from our institution after a COPD exacerbation are scheduled for a follow-up visit at 1 month. For reasons to do with 
statistical power, we conducted our analysis using data from the first exacerbation in each patient, despite the possibility of more than one admission during the observation period. The key exclusion criteria were as follows: 1) documented history of other concomitant chronic respiratory diseases (e.g. asthma, cystic fibrosis, or interstitial lung disease) or 2) community-acquired pneumonia, lung cancer, pulmonary embolism, pneumothorax, bronchiectasis, active pulmonary tuberculosis or acute heart failure identified by clinical signs, chest X-ray or computed tomography at admission.

An adverse outcome in COPD exacerbation was defined by the presence of at least one of the following: (1) death from a respiratory cause during hospitalisation or within 1 month of follow-up; (2) intensive care unit (ICU) admission; (3) invasive or non-invasive mechanical ventilation; and (4) COPD-related ER visit or readmission during follow-up. A good outcome was considered to exist in the absence of all the above-mentioned issues.

\section{Clinical characterisation}

Demographic and clinical data, including vital signs and laboratory findings, were collected within 3 hours of admission. The data included the patients' demographic variables, body mass index (BMI), smoking habit (former-smokers were defined as those having stopped smoking for 6 months or more prior to their participation in this study), chronic bronchitis (regular sputum production $\geq 3$ months in 2 consecutive years), use of long-term home oxygen therapy (LTHOT) or noninvasive ventilation 
(NIPPV) and comorbidities (using the Charlson index) [7]. Cigarette smoking history was collected as the smoking index (SI $=$ pack per day $\times$ smoking years). We also collected data about the numbers of COPD exacerbations in the preceding year. Dyspnoea of patients was evaluated by the modified British Medical Research Council (mMRC) scale. In addition, five variables were recorded at admission: heart rate, respiratory rate, blood pressure, temperature, and edema of both lower limbs.

\section{Spirometry measurements}

Spirometry measurement was based on the American Thoracic Society/European Respiratory Association guidelines [8]. Data were collected during the non-acute exacerbation phase (in the stable phase or 8 weeks after acute COPD exacerbation). Classification of COPD severity followed the Global Initiative for Chronic Obstructive Lung Disease [3]. Spirometry measurement was examined by German yag lung function instrument (Germany) and was performed by two experienced physicians.

\section{Sample collection and measurements}

We recorded gas exchange variables $(\mathrm{pH}$, partial arterial carbon dioxide pressure $\left[\mathrm{PaCO}_{2}, \mathrm{mmHg}\right]$ and the ratio of partial arterial oxygen pressure to the fraction of inspired oxygen $\left[\mathrm{PaO}_{2} / \mathrm{FiO}_{2}\right]$ using a Radiometer blood gas analyser (Leidomeit Medical Equipment Co., Ltd., Shanghai, China) at admission.

The vein blood was taken from the cubital vein of all subjects within 1 hour of admission and centrifuged immediately at $3000 \mathrm{rpm}$ for $15 \mathrm{mins}$ at $4{ }^{\circ} \mathrm{C}$. Then, the 
plasma and serum samples were stored at $-80^{\circ} \mathrm{C}$ until analysis. Whole blood leukocyte counts (WBC, 109/L) and eosinophils (EOS, 10\% $/ \mathrm{L}$ ) were measured using a Sysmex XE-2100 automated haematology analyser (Sysmex Medical Electronics Co., Ltd., Kobe, Japan). C-reactive protein (CRP, $\mathrm{mg} / \mathrm{L}$ ) levels were determined using a high-sensitivity immunoturbidimetric assay (Beckman Coulter Inc., Brea, CA, USA). Erythrocyte sedimentation rates (ESR, $\mathrm{mm} / \mathrm{h}$ ) were assessed using a TEST 1 ESR automatic analyser (ALIFAX Diagnostici, Padova, Italy). Albumin (g/L), blood urea nitrogen (BUN, mmol/L) and creatinine (umol/L) were assessed using an Hitachi 7600 automatic biochemical analyser (Hitachi, Tokyo, Japan). Troponin-I (ng/mL) was measured using an Access 2 Immunoassay system (Beckman Coulter). Brain natriuretic peptide $(\mathrm{BNP}, \mathrm{pg} / \mathrm{mL})$ and procalcitonin $(\mathrm{PCT}, \mathrm{ng} / \mathrm{mL})$ were measured using a Roche Cobas e411 automatic chemiluminescence immunoanalyser (Roche, Rutkreus, Switzerland).

The cytokines-interleukin-6 (IL-6) $(<5.9$ pg/mL), interleukin-8 (IL-8) $(<62$ $\mathrm{pg} / \mathrm{mL})$, interleukin-10 (IL-10) $(<9.1 \mathrm{pg} / \mathrm{mL})$, tumour necrosis factor- $\alpha(\mathrm{TNF}-\alpha)(<8.1$ $\mathrm{pg} / \mathrm{mL}$ ), and soluble IL-2 receptor (sIL-2R) (range $223-710 \mathrm{U} / \mathrm{mL}$ ) — were analysed using a chemiluminescence immunoassay (Siemens, Erlangen, Germany).

\section{Statistical analysis}

SPSS 21.0 statistical software (IBM Corp., Chicago, IL, USA) was used to perform data analysis. We report categorical variables as numbers and constituent 
ratios (\%), and we report continuous variables as means \pm standard deviations (SDs) or as medians (1st quartile; 3rd quartile) for normal and non-normal distributions, respectively. Categorical variables were compared using the chi-squared test or the Fisher exact test and on the measurement data using a one-way analysis of variance. Comparisons of parameters with skewed distributions were analysed using the Wilcoxon test. Multivariate logistic regression analyses were used for multivariate analysis to assess which background variables were predictive factors for poor prognosis in COPD exacerbation, and odds ratios were calculated with a 95\% confidence interval (CI). Pearson's correlation coefficient and Spearman's rho were used to analyse the correlation between predictors and other variables. The receiver operating characteristic (ROC) curve was used to determine the optimal diagnostic threshold for the predictors. Statistical significance was set at $\mathrm{P}<0.05$.

\section{Results}

\section{General characteristics of subjects}

The study population comprised 294 patients with COPD exacerbations, with a predominance of elderly men (250 mn [85\%]; age [mean+/-SD] 71.68+/- 8.48 years) and high smoking exposure (41 pack-years; Table 1). A further 17 cases were excluded because the COPD diagnosis was not confirmed by spirometry within 8 weeks of freedom from exacerbation (Figure 1). Table 1 presents the demographic and baseline characteristics of patients in each group. In the overall population, the mean body mass 
index was $22.41+/-3.11 \mathrm{~kg} / \mathrm{m}^{2}$, the mean $\mathrm{FEV}_{1} \%$ pred was $42.81 \%+/-17.47$, and the mean $\mathrm{FEV}_{1} / \mathrm{FVC}$ was $51.96 \%+/-10.37$. There were 10 patients $(3.4 \%)$ in GOLD stage A, 85 patients (28.9\%) in GOLD stage B, 123 patients (41.8\%) in GOLD stage C, and 76 patients $(25.9 \%)$ in GOLD stage D. Most of the patients had a history of chronic bronchitis (227 [77.2\%]) and had obvious symptoms of dyspnoea (170 patients with mMRC score 3-4). Comorbidities were common among the study population. The most prevalent comorbidity was congestive heart disease in 116 patients (40\%), followed by diabetes in 48 patients $(16 \%)$. The mean duration of hospitalisation was $12.4+/-4.8$ days.

One hundred and thirty-seven patients (47\%) had adverse outcomes in COPD exacerbation. Six patients died during hospitalisation and two during the 1-month follow-up period. One hundred and fifteen patients (39\%) were mechanically ventilated with either invasive or non-invasive ventilation or both, and admission to the ICU was required by 126 patients (43\%). Twenty-two patients (7.5\%) were hospitalised at least twice in a year for acute exacerbations (maximum five exacerbations). Twenty-one patients (7.1\%) were readmitted or attended the ER within 1 month after discharge.

\section{Comparison of patients with good and adverse outcomes in terms of clinical}

variables 
When compared with patients with good outcomes, patients with adverse outcomes had a greater pack-year smoking history $(\mathrm{P}=0.001)$, a higher proportion of chronic bronchitis history $(\mathrm{P}<0.001)$, more severe dyspnoea (mMRC 3-4, 83.2\% of the adverse outcomes group vs. mMRC $3-4,35.7 \%$ of the good outcomes group, $\mathrm{P}<$ 0.001), a significantly lower $\mathrm{FEV}_{1} \%$ pred $(\mathrm{P}<0.001)$ and $\mathrm{FEV}_{1} / \mathrm{FVC}$ ratio $(\mathrm{P}<0.001)$ and higher GOLD stage $(\mathrm{P}<0.001)$. As expected, the adverse outcomes patients used oxygen or non-invasive mechanical ventilation at home more frequently $(\mathrm{P}<0.001$ and $\mathrm{P}<0.001$, respectively) and had more frequent exacerbations within the previous year $(\mathrm{P}<0.001)$. On the day of admission, a significantly higher heart rate $(\mathrm{P}=0.005)$, a higher respiratory rate $(\mathrm{P}<0.001)$ and a higher rate of hypertension $(\mathrm{P}<0.001)$ were observed in the adverse outcomes group compared to the good outcomes group. In addition, edema of both lower limbs was more frequently observed in adverse outcomes patients $(\mathrm{P}<0.0001)$ (Table 1).

There were no significant differences attributable to age $(\mathrm{P}=0.157)$, gender $(\mathrm{P}=$ 0.19), BMI $(\mathrm{P}=0.284)$, or temperature upon arrival $(\mathrm{P}=0.774)$ among subjects in the good outcomes and adverse outcomes groups. Moreover, the rate of congestive heart disease was significantly higher in the adverse outcomes group compared to the good outcomes group $(\mathrm{P}<0.001)$, but there were no significant differences according to ischaemic heart disease $(\mathrm{P}=0.114)$, cerebrovascular disease $(\mathrm{P}=0.091)$, chronic kidney disease $(\mathrm{P}=0.073)$ or diabetes $(\mathrm{P}=0.322)$. 


\section{Comparison of patients with good and adverse outcomes in terms of laboratory}

\section{variables}

As shown in Table 2, the signs of respiratory failure at admission in terms of lower pH, lower $\mathrm{PaO}_{2} / \mathrm{FiO}$, and higher $\mathrm{PaCO}_{2}$ were also associated with adverse outcomes $(\mathrm{P}$ $<0.001, \mathrm{P}<0.001$, and $\mathrm{P}<0.001$, respectively). Serum PCT $(\mathrm{P}=0.006)$, TNT-I $(\mathrm{P}<$ 0.001), BNP $(\mathrm{P}<0.001)$, and BUN $(\mathrm{P}=0.006)$ were higher in the adverse outcomes group, while serum albumin was significantly lower, compared to the good outcomes group $(\mathrm{P}=0.001)$. Meanwhile, IL-6 ( $\mathrm{P}<0.001)$, IL-8 ( $\mathrm{P}=0.002), \mathrm{IL}-10(\mathrm{P}=0.01)$, TNF-a $(\mathrm{P}=0.001)$, and sIL-2R $(\mathrm{P}<0.001)$ were higher in the adverse outcomes group. There were no significant differences related to WBC $(\mathrm{P}=0.159), \mathrm{CRP}(\mathrm{P}=0.069)$, ESR $(P=0.252)$, EOS $(P=0.09)$, or serum creatinine $(P=0.721)$

\section{Predictors of adverse outcomes in COPD exacerbation}

Statistically significant variables from the univariate analysis were entered into a multivariate logistic regression model (Table 3). Greater smoking index, use of NIPPV at home, concomitant congestive heart disease, hypercapnia, and a higher level of sIL-2R were associated with adverse outcomes in COPD exacerbation. In the multivariate and multivariate adjusted analyses, the presence of hypercapnia at admission was the strongest predictor, and a high level of sIL-2R was confirmed as an independent predictor of adverse outcomes in COPD exacerbation. The probability of poor prognosis in patients with COPD exacerbation accompanied by congestive heart disease was 2.64 times higher than that in patients without congestive heart disease. 
Patients were divided into six groups based on $\mathrm{PaCO}_{2}$ : 1) group 1, less than 40 $\mathrm{mmHg}$; 2) group 2, $40 \mathrm{mmHg}$ to $49 \mathrm{mmHg}$; 3) group $3,50 \mathrm{mmHg}$ to $59 \mathrm{mmHg}$; ) group 4, $60 \mathrm{mmHg}$ to $69 \mathrm{mmHg}$; 5) group 5, $70 \mathrm{mmHg}$ to $79 \mathrm{mmHg}$; and 6) group 6, more than $80 \mathrm{mmHg}$. The odds ratio was 4.26 (95\% CI: 3.08-6.23, P < 0.001) per 10 mmHg. Patients were grouped into four quartiles according to serum sIL-2R: 1) quartile 1 , less than $550.25 \mathrm{U} / \mathrm{mL}$; 2) quartile $2,550.26 \mathrm{U} / \mathrm{mL}$ to $813.5 \mathrm{U} / \mathrm{mL} ; 3$ ) quartile $3,813.6 \mathrm{U} / \mathrm{mL}$ to $1099.25 \mathrm{U} / \mathrm{mL}$; and 4) quartile 4, more than $1099.26 \mathrm{U} / \mathrm{mL}$. The odds ratio was 2.75 (95\% CI: $1.89-4.18, \mathrm{P}<0.001)$. Patients were grouped into four quartiles according to the smoking index: 1) quartile 1, less than 14 pack-years; 2) quartile 2, 15 pack-years to 24 pack-years; 3) quartile 3, 25 pack-years to 49 pack-years; and 4) quartile 4, more than 50 pack-years. The odds ratio was 1.81 (95\% CI: 1.17-2.87, $\mathrm{P}=0.009)($ Table 4).

\section{Correlation between $\mathrm{PaCO}_{2}$, sIL-2R and other variables}

We found that among the other variables, the variables with reception areas under the ROC curve greater than 0.7 included $\mathrm{FEV}_{1}, \mathrm{FEV}_{1} / \mathrm{FVC}$, mMRC score, GOLD stage, BNP, TNT-I, and IL-6. We further analysed the correlation between $\mathrm{PaCO}_{2}$, sIL-2R, and these variables (Table 5). In all patients, $\mathrm{PaCO}_{2}$ was negatively correlated with $\mathrm{FEV}_{1} \%(\mathrm{P}<0.001)$ and $\mathrm{FEV}_{1} / \mathrm{FVC}(\mathrm{P}<0.001)$ and positively correlated with mMRC score $(\mathrm{P}<0.001)$ and GOLD stages $(\mathrm{P}<0.001)$, but not with BNP, TNT-I, IL-6, and sIL-2R. SIL-2R was only positively correlated with IL-6 (P < 0.001). 
When considering COPD exacerbation severity (Table 5), we found that patients in the good outcomes group had a negative correlation between $\mathrm{PaCO}_{2}$ and $\mathrm{FEV}_{1} \%(\mathrm{P}<$ $0.001)$ and a positive correlation between $\mathrm{PaCO}_{2}$ and GOLD stage $(\mathrm{P}<0.001)$, but no correlation with other variables. In the adverse outcomes group, we also found that $\mathrm{PaCO}_{2}$ was correlated with $\mathrm{FEV}_{1} \%(\mathrm{P}<0.001)$ and GOLD stage $(\mathrm{P}<0.001)$. sIL-2R was only positively correlated with IL-6 in both the good outcomes group and the adverse outcomes group $(\mathrm{P}<0.001)$, but not with other variables, suggesting that elevated serum sIL-2R level was an independent risk predictor for poor prognosis in COPD exacerbation.

\section{Diagnostic value of $\mathrm{PaCO}_{2}$ and sIL-2R for adverse outcomes in COPD}

\section{exacerbation}

Because $\mathrm{PaCO}_{2}$ had a remarkably higher concentration in COPD exacerbation with adverse outcomes and was negatively correlated with lower lung function, and sIL-2R was an independent risk factor for adverse outcomes in COPD exacerbation, we further investigated the possible merit of $\mathrm{PaCO}_{2}$ and sIL-2R in predicting prognosis in COPD exacerbation. ROC curve analysis indicated that the area under the curve (AUC) of $\mathrm{PaCO}_{2}$ to distinguish adverse outcomes in $\mathrm{COPD}$ exacerbation was 0.884 (95\% CI, $0.840-0.929$ ) (Figure 2). With a cut-off value of $54.25 \mathrm{mmHg}$, the sensitivity was $81.0 \%$ and the specificity was $93.6 \%$. The AUC of sIL-2R was 0.719 (95\% CI, $0.66-0.777$ ) (Figure 3). With a cut-off value of $860 \mathrm{U} / \mathrm{mL}$, the sensitivity was $62.0 \%$ and the specificity was $73.9 \%$. 


\section{Discussion}

This observational study of patients hospitalised for COPD acute exacerbation allowed us to make some important conclusions. First, a high level of sIL-2R was independently confirmed as a predictor of adverse outcomes in COPD acute exacerbation. Second, the presence of hypercapnia at admission was the strongest predictor of poor prognosis in COPD exacerbation. Hypercapnia was statistically associated with the severity of airflow obstruction. Third, we found that patients with poor outcomes in COPD exacerbation and a higher smoking index or combined with congestive heart disease were more likely to have a worse prognosis. More importantly, we demonstrated that circulating sIL-2R was independently associated with adverse outcomes in COPD exacerbation. These aspects of a patient presentation could help us identify patients who are at risk of worse outcomes and ultimately provide tailored interventions.

COPD is associated with chronic inflammation of the airways and lung parenchyma, which increases further during acute exacerbations and is also associated with systemic inflammation [9]. COPD exacerbation has been identified as a major clinical risk factor for future morbidity and mortality. Evidence suggests [10] that systemic inflammation can occur with the first symptoms of the disease, and COPD exacerbation is closely associated with an inflammatory cascade reaction. Theoretically, inflammatory biomarkers can be used to supplement clinical data and to determine the 
health status of patients before, during, and after the occurrence of COPD exacerbation $[11,12]$.

Over the past decade, many inflammatory biomarkers associated with COPD exacerbation have been investigated [13-15]. This study also found that the serum levels of IL6, IL8, IL10, and TNF- $\alpha$ were higher in patients with poor outcomes in COPD exacerbation compared to those with good outcomes. However, sIL-2R has not been reported to be associated with COPD exacerbation. Thus, it is necessary to conduct more research to explore the role of sIL-2R in COPD exacerbation.

IL-2 acts via the interleukin-2 receptor (IL-2R), which comprises $\alpha$ (CD25), $\beta$ (CD122), and common $\gamma$ (CD132) chains expressed on the surface of T cells [16]. IL-2R is released by T cells in a soluble form as sIL-2R. SIL-2R expression is increased with T cell activation. Hence, serum sIL-2R is considered a marker of T-cell activation [17]. Since its initial description, the detection and quantitation of sIL-2R has been increasingly used by researchers and clinicians in the investigation of immunologic phenomena in vitro and in vivo. sIL-2R is present in vivo, at low levels in the sera of healthy persons and, at markedly elevated levels, correlate with disease activity, such as in patients with cancer [18], infections [19], IgG4-related disease [20], autoimmune inflammation including rheumatoid arthritis [21] and systemic lupus erythematosus [22], but also in sarcoidosis patients [23]. 
Several studies have found that the level of sIL-2R is elevated during the acute or aggravated phase of the disease and decreased during the convalescence period or after treatment $[24,25]$. Park found [26,27] the concentrations of IL-2 and sIL-2R were higher in the bronchoalveolar lavage fluid (BALF) of symptomatic patients with bronchial asthma than those of normal subjects and asymptomatic patients. The concentration of sIL-2 inversely correlated with $\mathrm{FEV}_{1}$ in symptomatic bronchial asthma. Alexander also found [25] that the changes in the serum sIL2R concentration of asthma reflected disease severity and response to therapy and may be predictive of disease exacerbation. William [28] used daclizumab, which is a humanised monoclonal antibody that binds specifically to the $\alpha$ (Tac, CD25) subunit of the high-affinity sIL-2R and improves asthma control in patients with moderate to severe persistent asthma. In vitro studies conducted with daclizumab demonstrate that this antibody inhibits various lymphocyte functions, including IL-2-dependent mitogen- and antigen-induced T-cell proliferation and mixed lymphocyte reaction.

COPD is also a chronic airway disease, and there are greater numbers of macrophages, T-lymphocytes, and B-lymphocytes in the airway wall and parenchyma. In this study, sIL-2R was found to be significantly increased in patients with poor outcomes in COPD exacerbation, suggesting that sIL-2R may play a potential role in COPD exacerbation. 
In terms of inflammatory factors, it is important to mention that although IL-6, IL-8, IL-10 and TNF-a did not appear to be risk factors for adverse outcomes, they showed statistical significance on univariate analysis, which is consistent with some other research findings $[29,30]$. High concentrations of IL-6, which was positively correlated with sIL-2R, not only in all subjects but also in the grading analysis, may be associated with adverse outcomes in COPD exacerbation.

In the multivariate and multivariate adjusted analyses, the presence of hypercapnia at admission was the strongest predictor, which is consistent with Matkovic [31]. In addition, we observed that hypercapnia was negatively correlated with $\mathrm{FEV}_{1} \%(\mathrm{P}<0.001)$ in both the total population and in the subgroups, suggesting that hypercapnia is closely related to poor lung function.

In terms of complications, we found that congestive heart disease and hypertension, followed by diabetes were the most commonly associated complications in patients with COPD exacerbations. Concomitant congestive heart disease was associated with adverse outcomes in COPD exacerbations. The probability of poor prognosis in patients with COPD exacerbation accompanied by congestive heart disease was 2.64 times higher than that of patients without congestive heart disease. In addition, we found that patients with adverse outcomes had increased blood BNP and TNT-I levels as well as increased heart rate compared to good outcomes patients. Patel also revealed [32] that patients with frequent acute exacerbation of COPD had more 
severe arteriosclerosis than patients with infrequent acute exacerbation. The former patients had significantly increased blood BNP and TNT during acute exacerbation and continued to increase within 5 weeks after acute exacerbation. COPD patients with cardiovascular disease or even those with risk factors for cardiovascular disease are at an increased risk of cardiovascular events if they have COPD exacerbations. This is especially true in hospitalised patients and within the first 30 days after exacerbation [33]. As a result, patients with advanced moderate chronic obstructive pulmonary disease, such as concurrent congestive heart disease, should be the target of future research and intervention.

There were also some limitations to this study. First, there was a high proportion of males (85\%), which could affect the generalisability of the results. Second, only 294 people were recruited, which limited our analysis of the correlation between sIL-2R, lung function, and systemic inflammation in patients with COPD acute exacerbation. Third, we found that congestive heart disease was most common in patients with COPD exacerbation. However, we did not record echocardiographic results to better assess cardiac function. Finally, in future studies, we will need to analyse other samples that better reflect airway conditions, such as BALF and sputum.

\section{Conclusions}


In conclusion, findings from this study suggest that the presence of hypercapnia and elevated levels of serum sIL-2R increase the risk of adverse outcomes in COPD exacerbation. We analysed the diagnostic and predictive role of sIL-2R by analysing the ROC curve and binary logistic regression and found that sIL-2R could be an independent risk predictor of adverse outcomes in COPD exacerbation, suggesting that sIL-2R is worthy of further investigation in the future, thus advancing clinical practice toward precision medicine.

\section{Abbreviations}

Chronic obstructive pulmonary disease (COPD); Global Initiative on Chronic Obstructive Lung Disease (GOLD); per cent of predicted (\% pred); forced expiratory volume/forced vital capacity (FEV $/$ FVC); emergency room (ER); oral corticosteroids (OCS); intensive care unit (ICU); body mass index (BMI); long-term home oxygen therapy (LTHOT); noninvasive ventilation (NIPPV); smoking index (SI); modified British Medical Research Council (mMRC); partial arterial carbon dioxide pressure $\left[\mathrm{PaCO}_{2}\right]$; ratio of partial arterial oxygen pressure to the fraction of inspired oxygen (PaO2/FiO2); whole blood leukocyte counts (WBC); eosinophils (EOS); C-reactive protein (CRP); eythrocyte sedimentation rate (ESR); blood urea nitrogen (BUN); brain natriuretic peptide (BNP); procalcitonin (PCT); Troponin-I (TNT-I); interleukin-6 (IL-6); interleukin-8 (IL-8); interleukin-10 (IL-10); tumour necrosis factor- $\alpha$ (TNF- $\alpha$ ); 
soluble IL-2 receptor (sIL-2R); standard deviation (SD); confidence interval (CI); receiver operating characteristic (ROC); area under the curve (AUC).

\section{Declarations}

\section{Ethics approval and consent to participate}

The study protocol was approved by the Human Research Ethics Committee of the Xinhua Hospital affiliated to Shanghai Jiaotong University Medical College (XHEC-C-2017-085). Written informed consent was obtained from each participant. All experiments were performed in accordance with relevant guidelines and regulations.

\section{Consent for publication}

Not applicable.

\section{Availability of data and materials}

The datasets used and/or analysed during the current study are available from the corresponding author on reasonable request.

\section{Competing interests}

The authors declare that they have no competing interests in this section.

\section{Funding}


This work was supported by Hospital Foundation of Xinhua Hospital, to Yue Zhang, Shanghai Science and Technology Commission Grant of China, No:17511108502, 2017.7-2019.6

\section{Authors' contributions}

Xuejun Guo generated the hypothesis, directed the implementation. Fengfeng Han supervised the field activities and edited the manuscript. Yue Zhang contributed to data collection, statistical analyses and wrote the manuscript. Lianping Ren and Jinyuan Sun contributed to data collection and statistical analyses. All authors read and approved the final manuscript.

\section{Acknowledgements}

The authors thank all miner workers who participated in this study.

\section{References}

1. GBD 2017 disease and injury incidence and prevalence collaborators. Global, regional, and national incidence, prevalence, and years lived with disability for 354 diseases and injuries for 195 countries and territories, 1990-2017: a systematic analysis for the Global Burden of Disease Study 2017.Lancet. 2018;392:1789-858.

2. Han MK, Quibrera PM, Carretta EE, et al. Frequency of exacerbations in patients with chronic obstructive pulmonary disease: an analysis of the SPIROMICS cohort. The Lancet Respiratory medicine. 2017; 5: 619-26. 
3. Vogelmeier CF, Criner GJ, Martinez FJ, et al. Global strategy for the diagnosis, management, and prevention of chronic obstructive lung disease 2017 report: GOLD executive summary. Am J Respir Crit Care Med.2017 Mar 1;195(5):557-82.

4. Liu D, Peng SH, Zhang J, et al. Prediction of short term re-exacerbation in patients with acute exacerbation of chronic obstructive pulmonary disease. Int $\mathbf{J}$ Chron Obstruct Pulmon Dis. 2015 Jul 2;10:1265-73.

5. Ruparel M, López-Campos JL, Castro-Acosta A, et al. Understanding variation in length of hospital stay for COPD exacerbation: European COPD audit. ERJ Open Res. 2016;2(1):00034-02015.

6. Hurst JR, Vestbo J, Anzueto A, et al. Susceptibility to exacerbation in chronic obstructive pulmonary disease. N Engl J Med. 2010;363(12):1128-38.

7. Charlson ME, Pompei P, Ales KL, et al. A new method of classifying prognostic comorbidity in longitudinal studies: development and validation. $\mathbf{J}$ Chronic Dis.1987;40(5):373-83.

8. Brusasco V, Crapo R, Viegi G. Coming together: the ATS/ERS consensus on clinical pulmonary function testing. Eur Respir J. 2005;26:1-2.

9. Barnes PJ, Shapiro SD, Pauwels RA. Chronic obstructive pulmonary disease: molecular and cellular mechanisms. Eur Respir J. 2003 Oct;22(4):672-88.

10. J.C Hogg JC, F. Chu, S. Utokaparch, et al. The nature of small-airway obstruction in chronic obstructive pulmonary disease, New Engl. J. Med. 350 (26) (2004) 2645-53.

11. Cazzola M, Novelli G. Biomarkers in COPD. Pulm Pharmacol Ther.2010; 23:493-500.

12. Leeming DJ, Byrjalsen I, Sand JMB, et al. Evaluation of COPD Longitudinally to Identify Surrogate Endpoints (ECLIPSE) study investigators, Thal-Singer R, Miller BE, Karsdal MA, Vestbo J.Biomarkers of collagen turnover are related to annual change in $\mathrm{FEV}_{1}$ in patients with chronic obstructive pulmonary disease 
within the ECLIPSE study. BMC Pulm Med. 2017;17:164.

13. Alotaibi NM, Chen V, Hollander Z, et al. Phenotyping COPD exacerbations using imaging and blood-based biomarkers.Int $\mathbf{J}$ Chron Obstruct Pulmon Dis. $2018 ; 13: 217-29$.

14. Zheng J, Shi Y, Xiong L, et al. The Expression of IL-6, TNF- $\alpha$, and MCP-1 in Respiratory Viral Infection in Acute Exacerbations of Chronic Obstructive Pulmonary Disease. J Immunol Res. 2017;2017:8539294.

15. Sin DD, Hollander Z, DeMarco ML, et al. Biomarker Development for Chronic Obstructive Pulmonary Disease. From Discovery to Clinical Implementation. Am J Respir Crit Care Med. 2015;192:1162-70.

16. Turka L.A, Walsh P.T. IL-2 signaling and CD4+ CD25+ Foxp3+ regulatory T cells. Front. Biosci,2008, 13, 1440-46.

17. Rubin L.A, Nelson D.L. The soluble interleukin-2 receptor: biology, function, and clinical application. Ann. Intern. Med, 1990,113, 619-27.

18. Witkowska AM. On the role of sIL-2R measurements in rheumatoid arthritis and cancers. Mediators Inflamm. 2005; 2005(3):121-30.

19. Reddy M.M, Grieco M.H. Elevated soluble interleukin-2 receptor levels in serum of human immunodeficiency virus infected populations. AIDS Res. Hum. Retroviruses, 1988,4, 115-20.

20. Karim AF, Eurelings LEM, Bansie RD, et al. Soluble Interleukin-2 Receptor: A Potential Marker for Monitoring Disease Activity in IgG4-Related Disease. Mod Rheumatol. 2018 Sep;28(5):838-44.

21. Rubin LA, Snow KM, Kurman CC, et al. Serial levels of soluble interleukin 2 receptor in the peripheral blood of patients with rheumatoid arthritis: correlations with disease activity. J Rheumatol. 1990; 17(5):597-602.

22. ter Borg EJ, Horst G, Limburg PC, et al. Changes in plasma levels of interleukin-2 receptor in relation to disease exacerbations and levels of anti-dsDNA and complement in systemic lupus erythematosus. Clin Exp 
Immunol. 1990; 82(1):21-6.

23. Vorselaars AD, van Moorsel CH, Zanen P, et al. ACE and sIL-2R correlate with lung function improvement in sarcoidosis during methotrexate therapy. Respir Med. 2015; 109(2):279-85.

24. Eirini Mavropoulou, Nicolae-Catalin Mechie, Richard Knoop, et al. Association of serum interleukin-6 and soluble interleukin-2-receptor levels with disease activity status in patients with inflammatory bowel disease: A prospective observational study. PLoS One. 2020 May 29;15(5):e0233811.

25. Alexander AG, Barnes $\mathrm{NC}$, Kay $\mathrm{AB}$, et al. Clinical response to cyclosporin in chronic severe asthma is associated with reduction in serum soluble interleukin-2 receptor concentrations. Eur Respir J,1995 Apr;8(4):574-8.

26. Park CS, Lee SM, Chung SW, et al. Interleukin-2 and soluble interleukin-2 receptor in bronchoalveolar lavage fluid from patients with bronchial asthma. Chest.1994 Aug;106(2):400-6.

27. Park CS, Lee SM, Uh ST, et al. Soluble interleukin-2 receptor and cellular profiles in bronchoalveolar lavage fluid from patients with bronchial asthma. J Allergy Clin Immunol.1993 Feb;91(2):623-33.

28. William W. Busse Elliot Israel, Harold S. Nelson, James W. Baker, B. Lauren Charous, Donald Y. Young, Vladimir Vexler, Richard S. Shames, and the Daclizumab Asthma Study Group*. Daclizumab Improves Asthma Control in Patients with Moderate to Severe Persistent Asthma. Am J Respir Crit Care Med, 2008 Nov 15;178(10):1002-8.

29. Silva BSA, Lira FS, Ramos D, et al. Severity of COPD and its relationship with IL-10. Cytokine. 2018 Jun;106:95-100.

30. Bradford E, Jacobson S, Varasteh J, et al. The value of blood cytokines and chemokines in assessing COPD. Respir Res. 2017 Oct 24;18(1):180.

31. Matkovic Z, Huerta A, Soler N, et al. Predictors of adverse outcome in patients hospitalised for exacerbation of chronic obstructive pulmonary disease. 
Respiration 2012;84:17-26.

32. Patel AR, Kowlessar BS, Donaldson GC, et al. Cardiovascular risk, myocardial injury, and exacerbations of chronic obstructive pulmonary disease. Am J Respir Crit Care Med. 2013;188:1091-9.

33. Kunisaki KM, Dransfield MT, Anderson JA, et al. SUMMIT Investigators. Exacerbations of Chronic Obstructive Pulmonary Disease and Cardiac Events. A Post Hoc Cohort Analysis from the SUMMIT Randomized Clinical Trial. Am J Respir Crit Care Med. 2018; 198:51-7. 


\section{Figure legends}

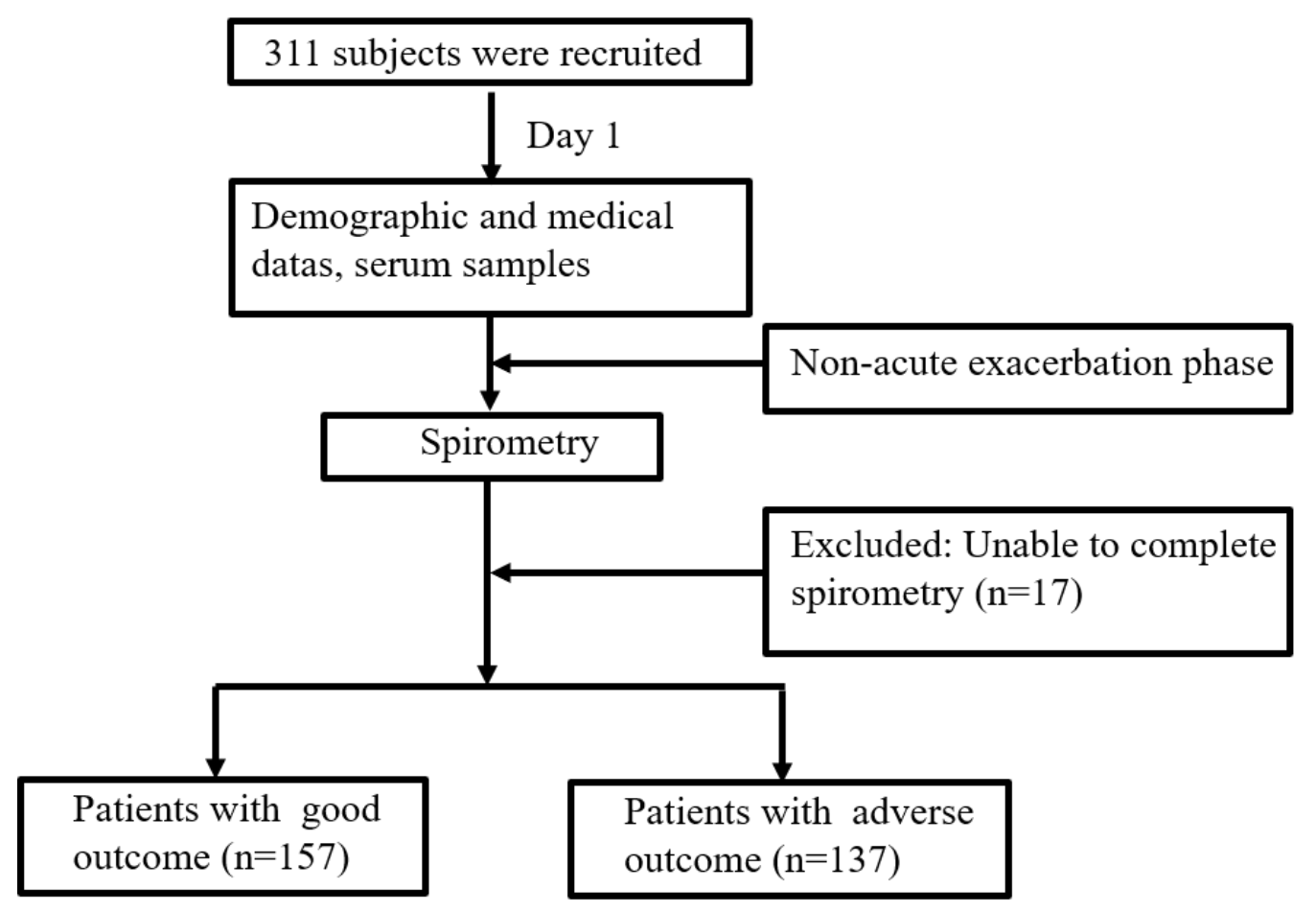

Figure 1 Study flow diagram 
Table 1 Baseline characteristics of the study population in relation to the outcome of COPD exacerbation

\begin{tabular}{|c|c|c|c|c|}
\hline Characteristics & $\begin{array}{l}\text { Total pop ulation } \\
\quad n=294\end{array}$ & $\begin{array}{c}\text { Patients with good } \\
\text { outcome } \\
n=157\end{array}$ & $\begin{array}{c}\text { Patients with adverse } \\
\text { outcome } \\
n=137\end{array}$ & $P_{\text {value }}$ \\
\hline \multicolumn{5}{|l|}{ Demographics } \\
\hline Male, $n(\%)$ & $250(85.0)$ & $138(87.9)$ & $112(81.8)$ & 0.19 \\
\hline Age, years & $71.68 \pm 8.48$ & $71.22 \pm 8.88$ & $72.17 \pm 7.88$ & 0.157 \\
\hline BMI, $\mathrm{kg}^{\prime} \mathrm{m}^{2}$ & $22.41 \pm 3.11$ & $22.6 \pm 3.1$ & $22.2 \pm 3.12$ & 0.284 \\
\hline Smoking status, n (\%) & & & & 0.86 \\
\hline Current Smoker, $\mathrm{n}(\%)$ & $125(42.5)$ & $68(43.3)$ & $57(41.6)$ & \\
\hline Former smoker, $\mathrm{n}(\%)$ & $169(57.5)$ & $89(56.7)$ & $80(58.4)$ & \\
\hline Smoking index, pack/year & $40.98 \pm 24.27$ & $37.48 \pm 24.19$ & $45.0 \pm 23.81$ & 0.001 \\
\hline \multicolumn{5}{|l|}{ Clinical variables } \\
\hline Chronic bronchitis, $\mathrm{n}(\%)$ & $227(77.2)$ & $99(63.1)$ & $128(93.4)$ & $<0.001$ \\
\hline mMRC , n $(\%)$ & & & & $<0.001$ \\
\hline $\operatorname{mMRC} 0-1, \mathrm{n}(\%)$ & $62(21.1)$ & $54(34.4)$ & $8(5.8)$ & \\
\hline $\mathrm{mMRC} 2, \mathrm{n}(\%)$ & $62(21.1)$ & $47(29.9)$ & $15(10.9)$ & \\
\hline $\operatorname{mMRC} 34, \mathrm{n}(\%)$ & $170(57.8)$ & $56(35.7)$ & $114(83.2)$ & \\
\hline $\mathrm{FEV}_{1}, \%$ pred & $42.81 \pm 17.47$ & $50.7 \pm 17.59$ & $33.76 \pm 12.17$ & $<0.001$ \\
\hline $\mathrm{FEV}_{1} / \mathrm{FVC}$ & $51.96 \pm 10.37$ & $55.6 \pm 10.1$ & $47.77 \pm 9.03$ & $<0.001$ \\
\hline GOLD 2017 stages, $n(\%)$ & & & & $<0.001$ \\
\hline Stage A & $10(3.4)$ & $9(5.7)$ & $1(0.7)$ & \\
\hline Stage B & $85(28.9)$ & $73(46.5)$ & $12(8.8)$ & \\
\hline Stage C & $123(41.8)$ & $56(35.7)$ & $67(48.9)$ & \\
\hline Stage D & $76(25.9)$ & $19(12.1)$ & $57(41.6)$ & \\
\hline Charlson index & $2(1,3)$ & $2(1,3)$ & $2(1,3)$ & 0.38 \\
\hline Ischaemic heart disease, n (\%) & $15(5.1)$ & $6(3.8)$ & $9(6.6)$ & 0.114 \\
\hline Congestive heart disease, $\mathrm{n}(\%)$ & $116(39.5)$ & $46(29.3)$ & $70(51.1)$ & $<0.001$ \\
\hline Cerebrovascular disease, $\mathrm{n}(\%)$ & $18(6.1)$ & $6(3.8)$ & $12(8.8)$ & 0.091 \\
\hline Diabetes, n $(\%)$ & $48(16.3)$ & $22(14.0)$ & $26(19.0)$ & 0.322 \\
\hline Chronic kidney failure, $n(\%)$ & $17(5.8)$ & $5(3.2)$ & $12(8.8)$ & 0.073 \\
\hline LTHOT, n $(\%)$ & $139(47.3)$ & $45(28.7)$ & $94(68.6)$ & $<0.001$ \\
\hline NIPPV at home, $\mathrm{n}(\%)$ & $36(12.2)$ & $1(0.6)$ & $35(25.5)$ & $<0.001$ \\
\hline Frequent COPD exacerbations, $\mathrm{n}(\%)$ & $142(48.3)$ & $47(29.9)$ & $95(69.3)$ & $<0.001$ \\
\hline \multicolumn{5}{|l|}{ Clinical sign } \\
\hline Heart rate, b'min, & $90(82,100)$ & $90(82,98)$ & $95(86,102)$ & 0.005 \\
\hline Respiratory rate, b/min & $22(20,25)$ & $20(20,22)$ & $24(20,26)$ & $<0.001$ \\
\hline Hypertension, $\mathrm{n}(\%)$ & $203(69.0)$ & $92(58.6)$ & $111(81.02)$ & $<0.001$ \\
\hline Body temperature, ${ }^{\circ} \mathrm{C}$ & $36.7(36.1,37.1)$ & $36.6(35.9,37)$ & $36.8(35.9,37.2)$ & 0.774 \\
\hline Edema of both lower limbs, $n(\%)$ & $61(20.7)$ & $18(11.5)$ & $43(31.4)$ & $<0.0001$ \\
\hline
\end{tabular}


Table 2 Laboratory variables at admission

\begin{tabular}{|c|c|c|c|c|}
\hline Characteristics & $\begin{array}{c}\text { Total population } \\
\qquad n=294\end{array}$ & $\begin{array}{l}\text { Patients with good } \\
\text { outcome } \\
n=157\end{array}$ & $\begin{array}{c}\text { Patients with adverse } \\
\begin{array}{c}\text { outcome } \\
n=137\end{array}\end{array}$ & $P$-value \\
\hline $\mathrm{pH}$ & $7.38 \pm 0.06$ & $7.40 \pm 0.04$ & $7.36 \pm 0.07$ & $<0.001$ \\
\hline $\mathrm{PaCO}_{2}, \mathrm{mmHg}$ & $53.58 \pm 18.58$ & $42.27 \pm 7.4$ & $66.53 \pm 19.08$ & $<0.001$ \\
\hline $\mathrm{PaO}_{2} / \mathrm{FiO}_{2}$ ratio & $242.36 \pm 21.62$ & $257.32 \pm 18.74$ & $225.21 \pm 32.96$ & $<0.001$ \\
\hline WBC, $10^{9} / \mathrm{L}$ & $8.35(6.3,11.78)$ & $8.3(6,11.4)$ & $8.6(6.9,11.8)$ & 0.159 \\
\hline $\mathrm{CRP}, \mathrm{mg} / \mathrm{L}$ & $35(9,85)$ & $28(8,81)$ & $45(12,92)$ & 0.069 \\
\hline $\mathrm{PCT}, \mathrm{ng} / \mathrm{ml}$ & $0.06(0.04,0.13)$ & $0.06(0.04,0.1)$ & $0.08(0.05,0.23)$ & 0.006 \\
\hline $\mathrm{ESR}, \mathrm{mm} / \mathrm{h}$ & $35.5(18,58)$ & $33(17,54)$ & $36(19,63)$ & 0.252 \\
\hline $\operatorname{EOS}, 10^{6} / \mathrm{L}$ & $48(22,110)$ & $80(22,120)$ & $44(22,110)$ & 0.09 \\
\hline TNT-I, ng/ml & $0.01(0.00,0.03)$ & $0.01(0.00,0.02)$ & $0.02(0.01,0.04)$ & $<0.001$ \\
\hline $\mathrm{BNP}, \mathrm{pg} / \mathrm{ml}$ & $248.5(96.4,594.2)$ & $169(70,361)$ & $378(140,790)$ & $<0.001$ \\
\hline Serum albumin, $g / L$ & $37.01 \pm 5.62$ & $35.84 \pm 4.31$ & $34.06 \pm 4.98$ & 0.001 \\
\hline $\mathrm{BUN}, \mathrm{mmol} / \mathrm{L}$ & $6.13(4.66,7.99)$ & $6.0(4.45,7.03)$ & $6.3(5.0,8.9)$ & 0.006 \\
\hline Creatinine, umol/L & $67(55.2,84.7)$ & $67(58,81)$ & $66(53,88)$ & 0.721 \\
\hline$\amalg-8, \mathrm{pg} / \mathrm{ml}$ & $28.1(16.5,52.1)$ & $23.4(14,45.2)$ & $36.4(20.2,53.9)$ & 0.002 \\
\hline IL-6, pg/ml & $14.85(8.27,24.5)$ & $12.8(5.09,19.7)$ & $18.9(11.0,27.5)$ & $<0.001$ \\
\hline $\mathbb{L}-10, \mathrm{pg} / \mathrm{ml}$ & $5(5,5.47)$ & $5.0(5.0,5.0)$ & $5.0(5.0,6.19)$ & 0.01 \\
\hline $\mathrm{TNF}-\alpha, \mathrm{pg} / \mathrm{ml}$ & $18.2(11.7,30.8)$ & $16.7(10.17,26.7)$ & $22.5(14.2,34.3)$ & 0.001 \\
\hline $\mathrm{SL}-2 \mathrm{R}, \mathrm{U} / \mathrm{ml}$ & $814(550,1099)$ & $695(473,888)$ & $968(734,1306)$ & $<0.001$ \\
\hline \multicolumn{5}{|c|}{ 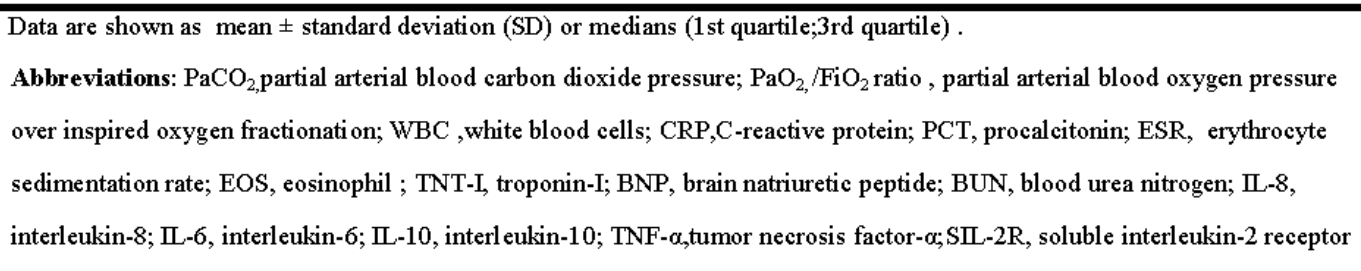 } \\
\hline
\end{tabular}


Table 3 Multivariate logistic regression analysis on the prediction of adverse outcome in COPD exacerbation

\begin{tabular}{lcccc}
\hline \multicolumn{1}{c}{ Parameter } & $\boldsymbol{\beta}$ & Odds Ratio & $\mathbf{9 5 \%} \mathrm{CI}$ & $\boldsymbol{P}$-value \\
\hline Smoking index, pack-years & 0.54 & 1.81 & 1.17 to 2.87 & 0.009 \\
Congestive heart disease & 0.97 & 2.64 & 1.24 to 5.83 & 0.013 \\
$\mathrm{NIPPV}$ at home & 3.01 & 20.24 & 3.18 to 398.64 & 0.007 \\
$\mathrm{PaCO}_{2}$ & 1.38 & 4.26 & 3.08 to 6.23 & $<0.001$ \\
$\mathrm{SIL-2R}$ & 1.01 & 2.75 & 1.89 to 4.18 & $<0.001$ \\
\hline
\end{tabular}

Abbreviations: Smoking index: number of cigarettes smoked per day $\times$ years of smoking; NIPPV: noninvasive ventilation; $\mathrm{S} L-2 \mathrm{R}$, soluble interleukin-2 receptor 
Table 4 Predictors of adverse outcome in COPD exacerbation

\begin{tabular}{|c|c|c|c|c|}
\hline Predictors & $\begin{array}{c}\text { Patients with } \\
\text { good outcome } \\
\quad n=157\end{array}$ & $\begin{array}{c}\text { Patients with adverse } \\
\begin{array}{c}\text { outcome } \\
n=137\end{array}\end{array}$ & Odds Ratio(95\%CI) & P-value \\
\hline Smoking index, pack-years & & & $1.81(1.17-2.87)$ & 0.009 \\
\hline$\leq 14, \mathrm{n}(\%)$ & $14(8.9)$ & $4(2.9)$ & & \\
\hline $15-24, \mathrm{n}(\%)$ & $37(23.6)$ & $13(9.5)$ & & \\
\hline $25-49, \mathrm{n}(\%)$ & $71(45.2)$ & $72(52.6)$ & & \\
\hline$\geqslant 50, \mathrm{n}(\%)$ & $35(22.3)$ & $48(35.0)$ & & \\
\hline $\mathrm{PaCO}_{2}, \mathrm{mmHg}$ & & & $4.26(3.08-6.23)$ & $<0.001$ \\
\hline$\leqslant 40, \mathrm{n}(\%)$ & $71(45.2)$ & $11(8.0)$ & & \\
\hline $40-49, \mathrm{n}(\%)$ & $61(38.9)$ & $14(10.2)$ & & \\
\hline $50-59, \mathrm{n}(\%)$ & $20(12.7)$ & $19(13.9)$ & & \\
\hline $60-69, \mathrm{n}(\%)$ & $4(2.5)$ & $40(29.2)$ & & \\
\hline $70-79, \mathrm{n}(\%)$ & $1(0.6)$ & $26(19.0)$ & & \\
\hline$\geqslant 80, \mathrm{n}(\%)$ & $0(0.0)$ & $27(19.7)$ & & \\
\hline SIL-2R, U/ml, & & & $2.75(1.89-4.18)$ & $<0.001$ \\
\hline$\leqslant 550.25, \mathrm{n}(\%)$ & $54(34.4)$ & $20(14.6)$ & & \\
\hline $550.26-813.5, \mathrm{n}(\%)$ & $48(30.6)$ & $25(18.2)$ & & \\
\hline $813.6-1099.25, \mathrm{n}(\%)$ & $35(22.3)$ & $38(27.7)$ & & \\
\hline$\geqslant 1099.26, \mathrm{n}(\%)$ & $20(12.7)$ & $54(39.4)$ & & \\
\hline
\end{tabular}


表 5 Correlation between $\mathrm{PaCO}_{2}$, SIL-2R and other variables in COPD exacerbation

\begin{tabular}{|c|c|c|c|c|c|c|}
\hline & \multicolumn{3}{|c|}{$\mathrm{PaCO} 2$} & \multicolumn{3}{|c|}{ SIL-2R } \\
\hline & $\begin{array}{c}\text { Total } \\
\text { population }\end{array}$ & $\begin{array}{c}\text { good } \\
\text { outcome }\end{array}$ & $\begin{array}{c}\text { adverse } \\
\text { outcome }\end{array}$ & $\begin{array}{c}\text { Total } \\
\text { population }\end{array}$ & $\begin{array}{c}\text { good } \\
\text { outcome }\end{array}$ & $\begin{array}{r}\text { adverse } \\
\text { outcome }\end{array}$ \\
\hline mMRC & $0.5^{* *}$ & 0.27 & 0.32 & 0.24 & 0.05 & 0.02 \\
\hline GOLD stage & $0.59 * *$ & $0.44 * *$ & $0.38^{* *}$ & 0.13 & 0.09 & 0.06 \\
\hline $\mathrm{FEV}_{1}, \%$ pred & $-0.58 * *$ & $-0.38 * *$ & $-0.39 * *$ & -0.17 & -0.04 & -0.04 \\
\hline $\mathrm{FEV}_{1} / \mathrm{FVC}$ & $-0.42 * *$ & -0.23 & -0.24 & -0.19 & -0.03 & -0.03 \\
\hline $\mathrm{PaCO}_{2}$ & - & - & - & 0.15 & 0.21 & 0.07 \\
\hline BNP & 0.15 & 0.06 & 0.12 & 0.29 & 0.05 & 0.26 \\
\hline TNT-I & 0.21 & 0.07 & 0.03 & 0.24 & 0.03 & 0.06 \\
\hline IL-6 & 0.07 & 0.14 & 0.12 & $0.59 * *$ & $0.37^{* *}$ & $0.44^{* *}$ \\
\hline SIL-2R & 0.15 & 0.21 & 0.07 & - & - & - \\
\hline
\end{tabular}




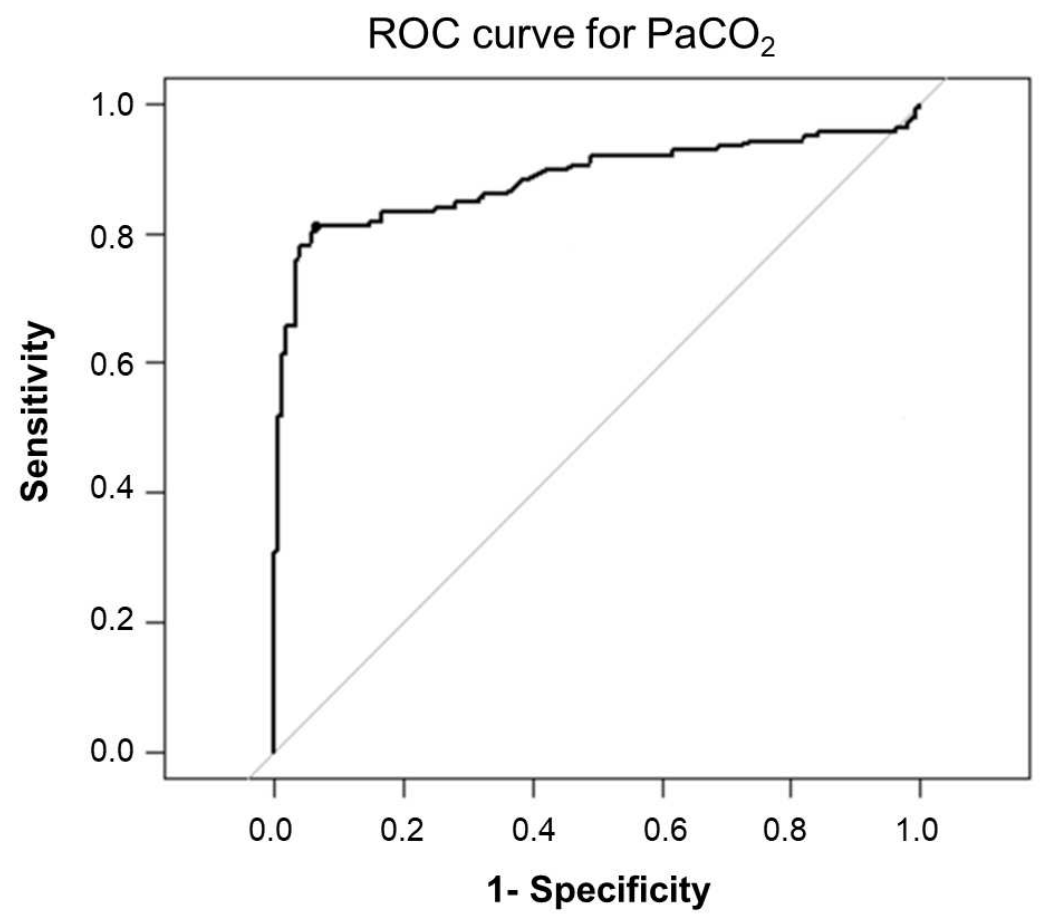

Figure 2 Diagnostic value of $\mathrm{PaCO}_{2}$ for adverse outcomes in COPD exacerbation 


\section{ROC curve for sIL-2R}

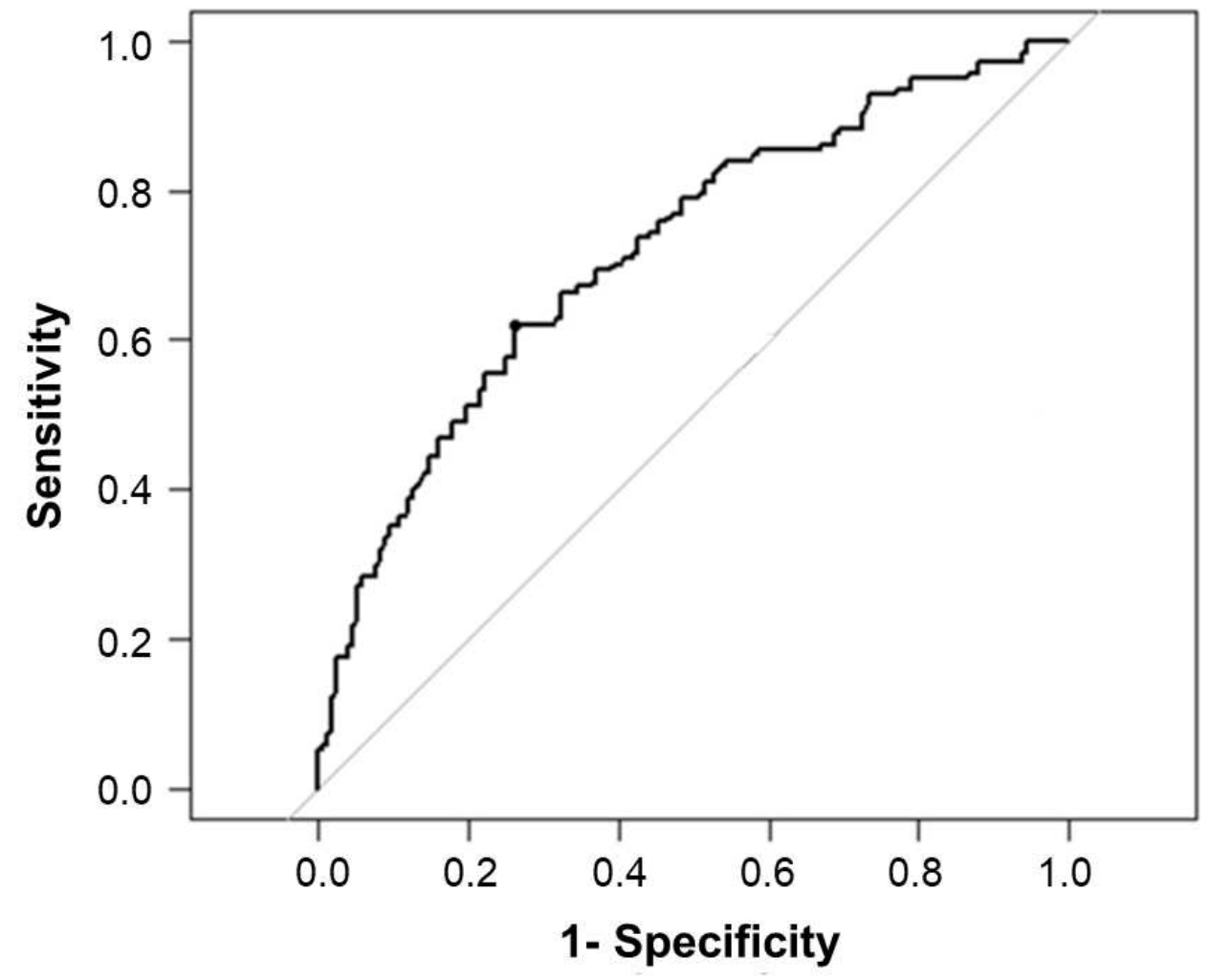

Figure 3 Diagnostic value of sIL-2R for adverse outcomes in COPD exacerbation 
Figures

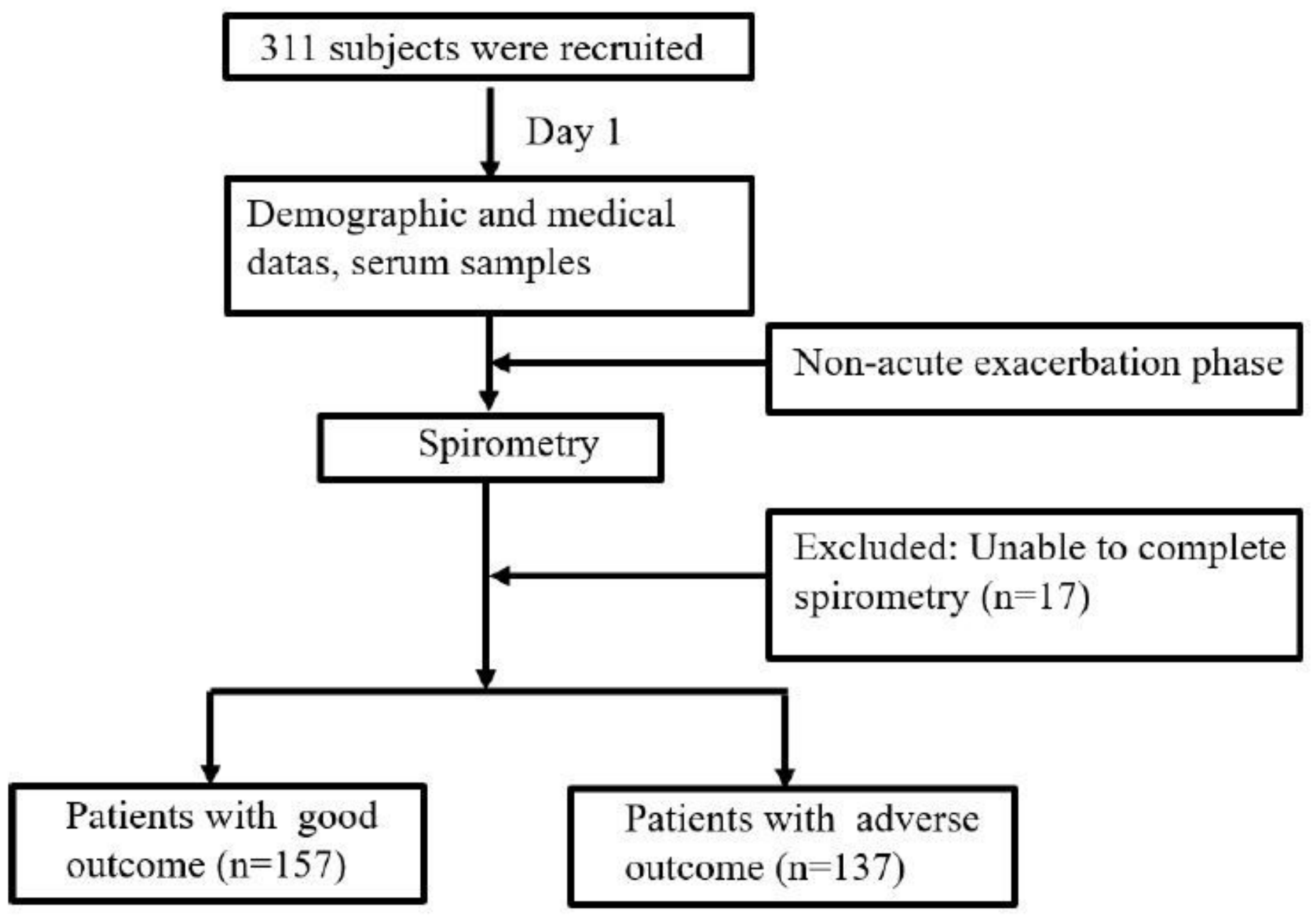

Figure 1

Study flow diagram 


\section{ROC curve for $\mathrm{PaCO}_{2}$}

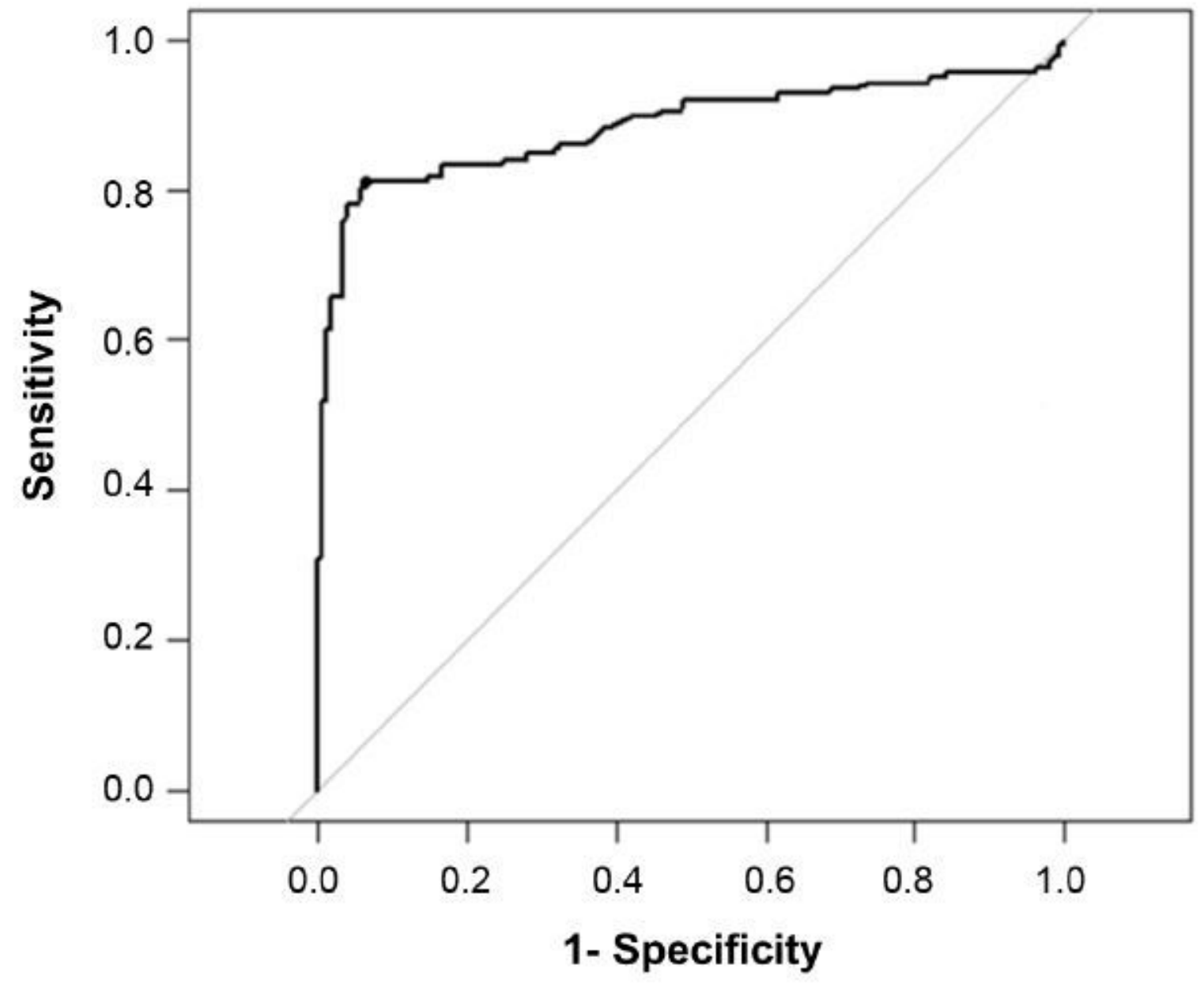

Figure 2

Diagnostic value of $\mathrm{PaCO} 2$ for adverse outcomesin COPD exacerbation 
ROC curve for sIL-2R

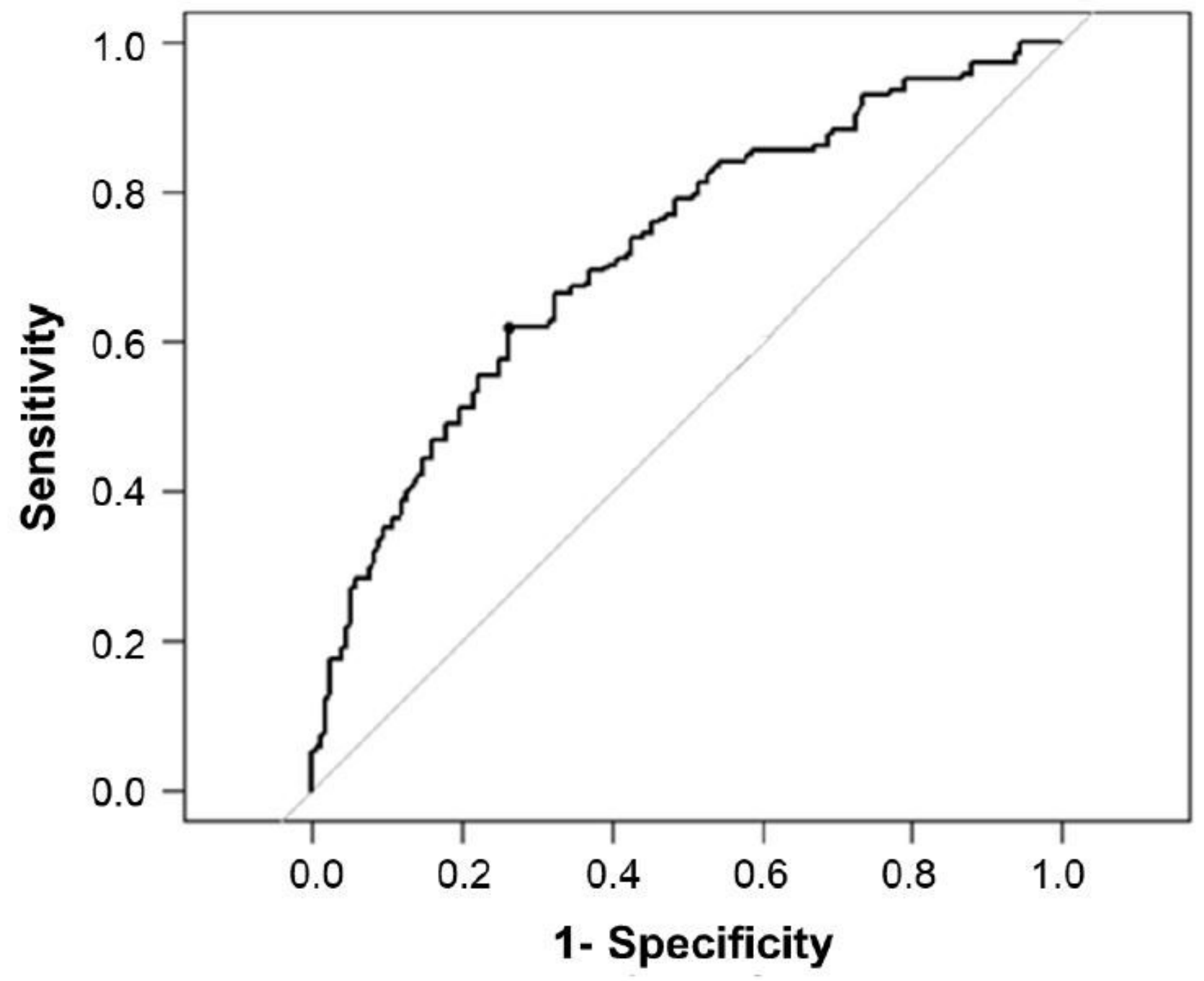

Figure 3

Diagnostic value of sIL-2R for adverse outcomesin COPD exacerbation 